\title{
QRISK2 Score in CABG Patients Correlated with Risk Factors
}

\author{
AMIN BAZYANI ${ }^{3,4}$, RAZAN AL NAMAT $^{1 *}$, MAURA GABRIELA FELEA ${ }^{1 *}$, IRINA IULIANA COSTACHE ${ }^{1 *}$, MIHAI CONSTANTIN², \\ VICTORITA SORODOC ${ }^{2}$, LAURENTIU SORODOC ${ }^{2}$, PAUL SIMION ${ }^{3,4}$, MIRELA MIHAELA MIHALCIA ${ }^{1}$, FLORIN MITU ${ }^{1}$, \\ GRIGORE TINICA 3,4 \\ ${ }^{1}$ Grigore T. Popa University of Medicine and Pharmacy, Faculty of Medicine, 1st Medical Department, 16 Universitatii Str., \\ 700115, lasi, Romania \\ ${ }^{2}$ Grigore T. Popa University of Medicine and Pharmacy, Faculty of Medicine, 3rd Medical Department, 16 Universitatii Str., \\ 700115, Iasi, Romania \\ ${ }^{3}$ Grigore T. Popa University of Medicine and Pharmacy, 16 Universitatii Str., 700115, Iasi, Romania \\ ${ }^{4}$ Institute for Cardiovascular Diseases, 50 Carol I Blvd., 700503, Iasi, Romania
}

\begin{abstract}
Guidelines for primary prevention suggested using any risk score, among those QRISK2, identifying the high-risk populations. The purpose of this study was to determine whether the QRISK2Score would register changes in patients with coronary artery disease demanding acute or postponed CABG intervention. The QRISK2Score was performed the day of admission after the clinical examination and blood test results, and immediately after $C A B G$ surgery (in the first week post-CABG, in an interval of 24 hours to 7 days) having another blood test evaluation. The 120 patients admitted in the Clinic of Cardiovascular Surgery of the Institute of Cardiovascular Disease met the inclusion criteria: CABG patients (less than 1 week), aged 40-85 years old, $B M I>25 \mathrm{~kg} / \mathrm{m}^{2}$, and mixed dyslipidemia. In both phases, for every patient, it was performed a clinical examination, a set of hematological, biochemical, lipid, coagulation and inflammatory profile, and ECG and echocardiography. Our research on hospitalized patients undergoing CABG, by comparing the Phase I and Phase III results, revealed that the median 10-year QRISK2 cardiovascular risk score waS approximately $47.88 \%$ lower $(p=0.000)$ in the first week after cardiac surgery. QRISK2 score gives a more appropriate risk estimation based on the social component, thus identifying high risk patients associating social deprivation. Comparative to Framingham risk score, QRISK2 score, by including additional variables, proves the efficacy of lifestyle changes and management decisions, and sustaines the treatment directed towards modifying variables or risk factors.
\end{abstract}

Keywords: QRISK2 score, coronary artery disease, CABG, cardiovascular disease prevention

According to the European Guide 2016 on cardiovascular disease prevention, the benefit of simple risk scores was to predict long-term morbidity and subsequent mortality: Framingham Risk Score (FRS), ASSIGN, QRISK1 \& QRISK2, PROCAM. The most common clinical tool, used to estimate the risk level of coronary artery disease (CAD), to identify men and women at high risk susceptible to changing risk factors in order to prevent future cardiovascular events, is the Framingham Risk Score (FRS). FRS components comprise gender, age, smoking status, systolic blood pressure and lipid profile. FRS can indicate the possible benefits of prevention, being useful for the patient and clinician to choose lifestyle changes and/or preventive medical treatment [1].

A large number of risk assessment scores have been developed to help clinicians determine the long-term risk of cardiovascular diseases (CVD). In primary prevention, the Framingham, ASSIGN and QRISK2 scores are widely used to predict CVD risk at 10 years. The Framingham risk score is based on an American cohort a few decades ago. The ASSIGN risk score was derived from the Scottish Extended Health School and the QRISK risk score from a large primary care database in England and Wales. These scores were based on risk factors that can be easily assessed and measured in the general population. Framingham, ASSIGN and QRISK2 risk scores were validated by comparison with the predicted risks in the total population [2]. There is no consensus on which risk score to be used for CVD risk assessment. Guidelines for primary prevention suggested using any risk score [3]. These three risk scores are currently used in the UK to determine the risk of CVD. Two validation studies for QRISK2 reported that the predicted and observed risks were on average similar and concluded that QRISK2 was accurate in identifying a high-risk population $[4,5]$.

In 1968, Rene Favaloro introduced the Coronary Artery Bypass Grafting (CABG) as the first technique for myocardial revascularization, which suffered some methodological changes later on [6]. Another change was the indication of CABG for particular groups of patients, such as patients with more complex coronary anatomy, defined by a Syntax score greater than 22, and patients presenting comorbidities like diabetes mellitus and chronic kidney disease in stage 4 and $5[7,8]$.

\section{Experimental part \\ Material and methods}

The 120 individuals comprised in the study group were admitted in the Clinic of Cardiovascular Surgery of the Institute for Cardiovascular Diseases.

All subjects who participated in the research signed in the informed consent, certifying that they agree with the investigations, blood tests and treatment mandatory to be performed, as well as with the final publication of the data in scientific form and under permanent protection of anonymity. The study was endorsed by the Research Ethics Committee of the Grigore T. Popa University of Medicine and Pharmacy of lasi.

The purpose of this study was to determine whether the QRISK2 Score would register changes in patients with coronary artery disease demanding acute or postponed CABG intervention. The QRISK2 Score was performed the 
day of admission after the clinical examination and blood test results, and immediately after CABG surgery (in the first week post-CABG, in an interval of 24 hours to 7 days) having another blood test evaluation.

\section{Statistical analysis}

The database was compiled in Microsoft Office Excel 2010 version, and statistical analysis was performed in the IBM SPSS Statistics v.20. We computed the averages, frequencies, standard deviations, differences between the maximum and minimum values of the numerical parameters.

The statistical significance of the difference between two frequencies was determined by the Chi-square test of independence. The t-Student test was used to reveal the significance of the difference between two average values. The threshold values for $p$ were considered $<0.05$, providing a statistical significance level of the test. The regression equations and correlation coefficients were also calculated.

\section{Results and discussions}

The 120 patients admitted in the Clinic of Cardiovascular Surgery of the Institute of Cardiovascular Disease met the inclusion criteria: CABG patients (less than 1 week), aged 40-85 years old, $\mathrm{BMI}>25 \mathrm{~kg} / \mathrm{m}^{2}$, and mixed dyslipidemia.

In both phases, for every patient, it was performed a clinical examination, a set of hematological, biochemical, lipid, coagulation and inflammatory profile, and ECG and echocardiography.

Blood pressure and heart rate were monitored daily in the Intensive Care Unit, and then twice a day.

Glucose plasma level was monitored once daily and more frequent in case of diabetic patients. Renal function was evaluated by serum urea, creatinine and uric acid level. Creatinine (2-Amino-1-methyl-5H-imidazol-4- one), an importantindicator of renal function, is byproduct of the muscle metabolism that is excreted unchanged. Glomerular filtration rate (GFR) was calculated according to the most accurate formula of CKDEPI (Chronic Kidney Disease Epidemiology Collaboration) [9]:

eGFR = $141 \times \min (\mathrm{SCr} / \mathrm{k}, 1) \alpha \times \max (\alpha \mathrm{Cr} / \mathrm{k}, 1)-1.209 \times$ 0.993Age $x$ [1.018 if Female]

[SCr $=$ serum creatinine $(\mathrm{mg} / \mathrm{dL}) ; \mathrm{k}=0.7$ for females and 0.9 for males; $\alpha=-0.329$ for females and -0.411 for males; $\min =$ the minimum of $\mathrm{SCr} / \mathrm{k}$ or 1 , and $\max =$ the maximum of $\mathrm{SCr} / \mathrm{k}$ or 1 ).

QRISK $® 2$ is a well established cardiovascular disease (CVD) risk score used in the NHS since 2009, that is designed to identify people at high risk of developing CVD, who need to be more thoroughly assessed to reduce their risk of developing CVD [10,11].

The QRISK ${ }^{\circledR} 2$ score, estimating the risk of a person to develop CVD over the next 10 years, was specifically developed by physicians and academics to be used in the UK. In the British Medical Journal in July 2007 and in the journal Heart in J anuary 2008, it was published the original research that substantiates QRISK score $[10,11]$. The QRISK2 score includes age, gender, ethnicity, smoking status, and presence/ absence of diabetes, chronic kidney disease (stage 4 or 5), atrial fibrillation, antihypertensive treatment, rheumatoid arthritis, and family history of angina pectoris or myocardial infarction in a first degree relative younger than 60 years old; laboratory item includes ratio of total serum cholesterol to high density lipoprotein (HDL)cholesterol ratio; the functional items include the values for systolic blood pressure, height and weight, thus alowing to calculate the body mass index (BMI). The laboratory and functional parameters are more variable and susceptible to changes.

A score is assigned to each level of every risk factor, and the total score is calculated by adding all the points. The

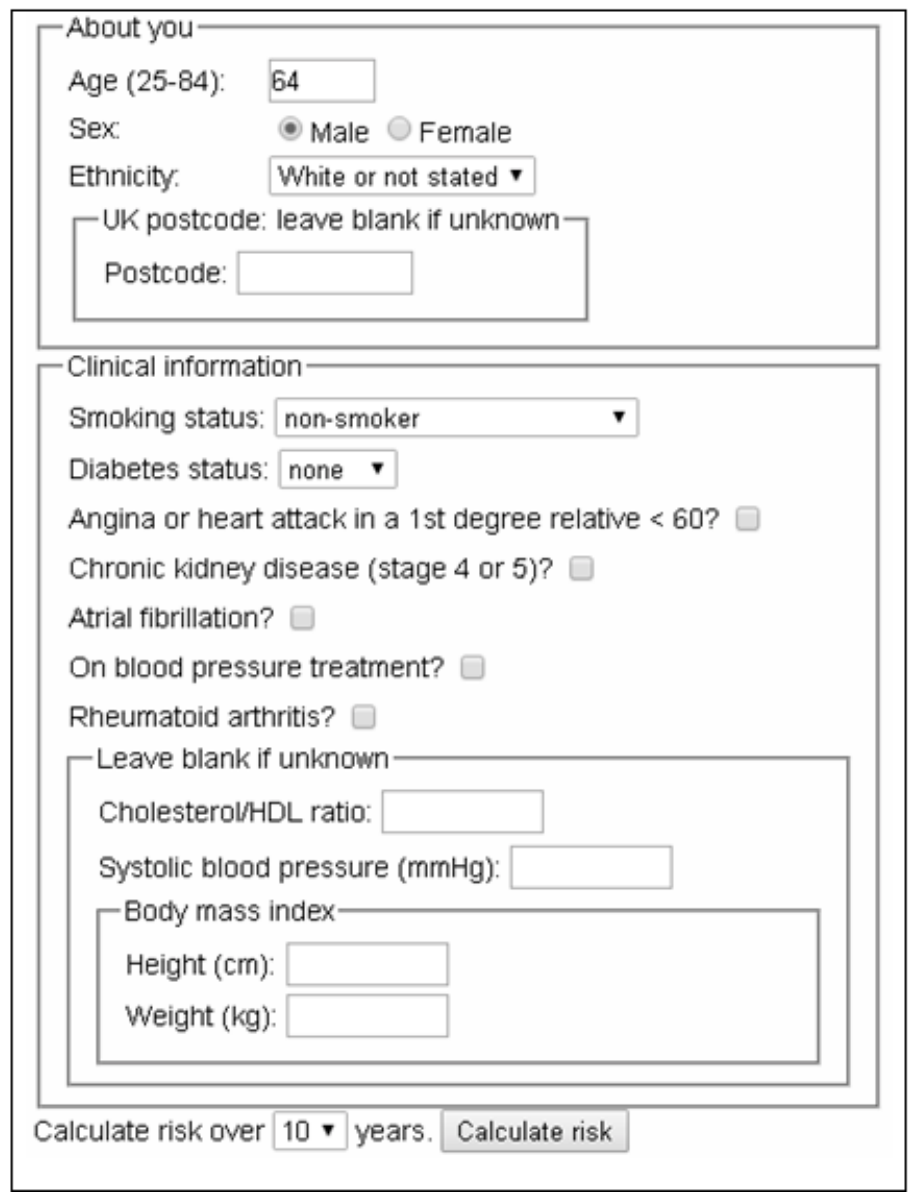

Fig. 1. The QRISK2 Score (https://qrisk.org/ 2016/) 
sum of these points provides cardiovascular risk assessment, estimated over the next 10 years.

If someone has a 10 years -QRISK $~ R 2$ score of $20 \%$, then, out of a group of 100 people like these, on average, 20 people would develop cardiovascular disease over the next 10 years, or else they have one chance of five to be affected by one or more CVD over the next 10 years.

\section{Statistical analysis}

The database was compiled in Microsoft Office Excel 2010 version, and statistical analysis was performed in the IBM SPSS Statistics v.20. We computed the averages, frequencies, standard deviations, differences between the maximum and minimum values of the numerical parameters. The statistical significance of the difference between two frequencies was determined by the Chisquare test of independence. The t-Student test was used to reveal the significance of the difference between two average values. The threshold values for $p$ were considered $<0.05$, providing a statistical significance level of the test. The regression equations and correlation coefficients were also calculated.

The patients included in the group were aged between 41 and 85 years. The group characteristics at the admission, Phase I, before the CABG was performed, are detailed in table 1.

In Phase III, patients' characteristics (table 2) suffered significant changes, with amelioration of blood pressure control, lipid profile and body mass index. It is to be mentioned that those who were smokers at the admission, ceased to smoke after the cardiac surgery.

Our research on hospitalized patients undergoing CABG, by comparing the Phase I and Phase III results, revealed that the median 10-year QRISK2 cardiovascular risk score was approximately $47.88 \%$ lower $(p=0.000)$ in the first week after cardiac surgery (fig. 2).

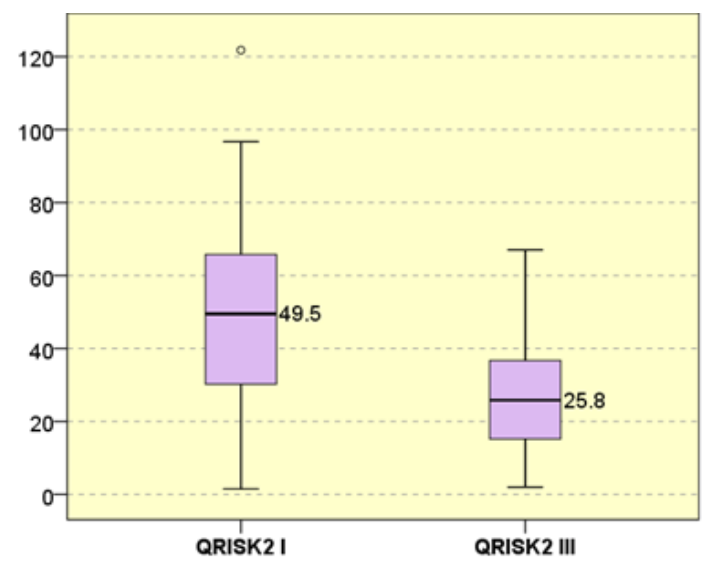

Fig. 2. Box-plot Diagram - Patients distribution on the QRISK2 cardiovascular score in Phase I and III after CABG

The mean risk score value (50.7) in Phase I was similar to the median value (49.5), the same concordance being revealed also for Phase III risk scores (28.05 vs. 25.08) (table 3). The difference between the phases, as shown in the box-plot above is about $50 \%$.

The mean and median changes of QRISK2 was more important in patients previously diagnosed with type 2 Diabetes Mellitus, or in patients with chronic kidney disease (from stage 2 to stages 4 and 5) (table 4).

QRISK2 Score indirectly revealed another major change that is not previewed in the score components: the glomerular filtration function (fig. 3).

The study age group was ranged between 40 to 85 years old. It was considered the optimal range because cardiovascular risk in this age groups should be determined steadily, and possible further investigations are needed to evaluate true vascular age.

Framingham Score was the early well documented strategy to identify cardiac and cardiovascular risk factors,

Table 1

CHARACTERISTICS OF PATIENTS UNDERGOING CABG, AGED 41 TO 85 YEARS, AND ELIGIBLE FOR THE STUD

\begin{tabular}{|c|c|c|}
\hline Characteristics & $\begin{array}{c}\text { Women } n=29 \\
(24.17 \%)\end{array}$ & $\begin{array}{c}\text { Men } n=91 \\
(75.83 \%)\end{array}$ \\
\hline Mean (SD) age (years) & $67.34(8.67)$ & $65.47(10.18)$ \\
\hline Mean (SD) body mass index $\left(\mathrm{kg} / \mathrm{m}^{2}\right)-$ Phase I & $28.76(4.40)$ & $29.63(2.43)$ \\
\hline Mean (SD) systolic blood pressure (mm Hg) - Phase I & $151.03(6.18)$ & $157.42(6.72)$ \\
\hline Mean (SD) diastolic blood pressure (mm Hg) - Phase I & $85(6.81)$ & $90.71(6.26)$ \\
\hline Mean (SD) total cholesterol to HDL cholesterol ratio - Phase I & $5.96(3.79)$ & $5.25(2.72)$ \\
\hline Mean (SD) total cholesterol - Phase I & $193.8(61.04)$ & $177.64(40.24)$ \\
\hline Mean (SD) HDL cholesterol - Phase I & $38(10.65)$ & $40.89(23.68)$ \\
\hline Mean (SD) LDL cholesterol - Phase I & $147.86(19.98)$ & $143.11(33.43)$ \\
\hline Mean (SD) TG - Phase I & $142.76(61.55)$ & $149.60(55.66)$ \\
\hline \multicolumn{3}{|l|}{ Smoking status: } \\
\hline Non-smoker & $19(15.83 \%)$ & $28(23.33 \%)$ \\
\hline \multicolumn{3}{|l|}{ Current smoker (cigarettes/day): } \\
\hline Light $(\bullet 10)$ & $10(8.33 \%)$ & 0 \\
\hline Heavy $(\geq 20)$ & 0 & $63(52.5 \%)$ \\
\hline Ethnic group: White & $120(100 \%)$ & $120(100 \%)$ \\
\hline
\end{tabular}

Table 2

CHARACTERISTICS OF PATIENTS' PARAMETERS ONE-WEEK AFTER CABG

\begin{tabular}{|l|c|c|}
\hline Characteristics & $\begin{array}{c}\text { Women } \mathrm{n}=29 \\
(24.17 \%)\end{array}$ & $\begin{array}{c}\text { Men } \mathrm{n}=91 \\
(75.83 \%)\end{array}$ \\
\hline Mean (SD) age (years) & $67.34(8.67)$ & $65.47(10.18)$ \\
\hline Mean (SD) body mass index (kg/m²) - Phase III & $27.66(4.61)$ & $28.33(0.03)$ \\
\hline Mean (SD) systolic blood pressure (mm Hg) - Phase III & $128.28(6.98)$ & $130.49(5.17)$ \\
\hline Mean (SD) diastolic blood pressure (mm Hg) - Phase III & $73.62(5.33)$ & $76.43(8.31)$ \\
\hline Mean (SD) total cholesterol to HDL cholesterol ratio - Phase III & $3.77(1.64)$ & $4.33(3.82)$ \\
\hline Mean (SD) total cholesterol - Phase III & $175.76(47.56)$ & $165.66(49.28)$ \\
\hline Mean (SD) HDL cholesterol - Phase III & $51.23(14.39)$ & $50.04(28.19)$ \\
\hline Mean (SD) LDL cholesterol - Phase III & $126.48(22.72)$ & $120.60(30.52)$ \\
\hline Mean (SD) TG - Phase III & $143.41(57.60)$ & $129.20(56.68)$ \\
\hline
\end{tabular}


Table 3

DESCRIPTIVE STATISTICS OF QRISK2 CHANGES BETWEEN PHASE I AND PHASE III

\begin{tabular}{|l|r|r|r|r|r|r|r|r|}
\hline \multirow{2}{*}{$\begin{array}{l}\text { Descriptive } \\
\text { statistics }\end{array}$} & & \multicolumn{9}{|c|}{ Statistic } \\
\cline { 2 - 9 } & Mean & \multicolumn{2}{|c|}{$\begin{array}{c}95 \% \text { Confidence } \\
\text { Interval for Mean }\end{array}$} & Median & $\mathbf{n}$ & $\begin{array}{c}\text { Std. } \\
\text { Deviation }\end{array}$ & Minimum & Maximum \\
\cline { 2 - 9 } & & $\begin{array}{l}\text { Lower } \\
\text { Bound }\end{array}$ & $\begin{array}{c}\text { Upper } \\
\text { Bound }\end{array}$ & & & & & \\
\hline QRISK2-1 & 50.70 & 46.42 & 54.98 & 49.50 & 120 & 23.67 & 1.50 & 121.80 \\
\hline QRISK2-III & 28.05 & 25.16 & 30.93 & 25.80 & 120 & 15.96 & 2.00 & 67.00 \\
\hline
\end{tabular}

Table 4

DESCRIPTIVE STATISTICS OF QRISK2 CHANGES IN PATIENTS WITH TYPE 2 DIABETES MELLITUS AND IN PATIENTS WITH CKD

\begin{tabular}{|c|c|c|c|c|c|c|c|c|}
\hline & & \multicolumn{7}{|c|}{ Descriptive Statistics } \\
\hline & & \multirow[b]{2}{*}{ Mean } & \multicolumn{2}{|c|}{$\begin{array}{l}95 \% \text { Confidence } \\
\text { Interval for Mean }\end{array}$} & \multirow[b]{2}{*}{ Median } & \multirow[b]{2}{*}{$\begin{array}{c}\text { Std. } \\
\text { Deviation }\end{array}$} & \multirow[b]{2}{*}{ Minimum } & \multirow[b]{2}{*}{ Maximum } \\
\hline & & & $\begin{array}{l}\text { Lower } \\
\text { Bound }\end{array}$ & $\begin{array}{l}\text { Upper } \\
\text { Bound }\end{array}$ & & & & \\
\hline \multirow[t]{2}{*}{ Dif. QRISK2 III - I } & No DM & -20.01 & -24.01 & -16.01 & -18.40 & 14.81 & -101.40 & 4.80 \\
\hline & $\mathrm{T}^{2} \mathrm{DM}$ & -24.89 & -29.31 & -20.47 & -21.30 & 17.85 & -66.70 & 6.00 \\
\hline \multirow[t]{2}{*}{ Dif. QRISK2 III - I' } & No $\mathrm{CKD}^{-}$ & -20.89 & -24.68 & -17.10 & $-16.00^{-}$ & 17.57 & -101.40 & 4.80 \\
\hline & $\mathrm{CKD}^{--}$ & -26.94 & -31.54 & -22.33 & -25.80 & 13.40 & -66.70 & 6.00 \\
\hline
\end{tabular}

Table 5

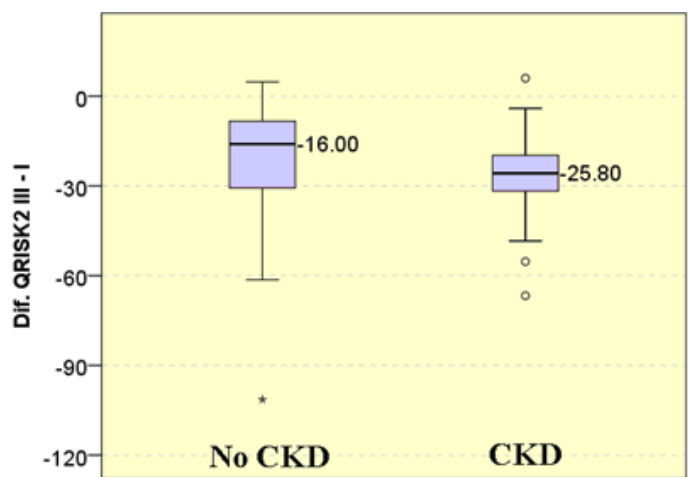

Fig. 3. Box-plot Diagram - Patients (with CKD) distribution on the QRISK2 cardiovascular score in Phase I and III after CABG
ITEMS INCLUDED IN SCORE, FRS AND QRISK2

\begin{tabular}{|l|l|l|l|}
\hline & SCORE & FRS & QRISK2 \\
\hline Age & & & \\
\hline Sex & & & \\
\hline Ethnicity & & & \\
\hline Systolic Blood Pressure & & & \\
\hline Total Cholesterol & & & \\
\hline HDL Cholesterol & & & \\
\hline Total Chol to HDL-Chol Ratio & & & \\
\hline Smoking Status & & & \\
\hline Diabetes & & & \\
\hline Antihypertensive Treatment & & & \\
\hline Family History of CVD & & & \\
\hline Chronic Kidney Disease (stage 4 or 5) & & & \\
\hline Atrial Fibrillation & & & \\
\hline Rheumatoid Arthritis & & & \\
\hline Weight, Height, Body Mass Index & & & \\
\hline High Sensitivity C-Reactive Protein & & & \\
\hline
\end{tabular}

thus estimating and stratifying the 10 -year cardiovascular risk of an individual to develop coronary heart disease.

By comparison, QRISK2 Score includes more components than FRS and SCORE (table 5).

Along the years of medical research, a great number of diagnostic tools, as coronary angiography, and methods were created and used on patients suffering from coronary artery disease (CAD) [12].

Although it is costly and invasive, coronary angiography remains the gold standard for diagnosing the acute form or the chronic but significant coronary obstructive disease, and pointing out toward the optimal treatment choice.

As medical and surgical revolution in cardiovascular disease showed us along the years, and because of the multiple risk factors for CAD, several risk assessment tools may be used to try and estimate the risk of this pathology within the different age groups [13].

$C A B G$ proved to be effective in reducing the value of different parameters reflecting cardiac ischemia, and also in ameliorating the cardiovascular risk scores $[14,15]$.

\section{Conclusions}

QRISK2 score gives a more appropriate risk estimation based on the social component, thus identifying high risk patients associating social deprivation. Comparative to
Framingham risk score, QRISK2 score, by including additional variables, proves the efficacy of lifestyle changes and management decisions, and sustaines the treatment directed tow ards modifying variables or risk factors.

\section{Limitations}

Encountered limitations reffered to the follow-up of the study group for more than to years, in order to review the QRISK2 Score evolution, and to stratify the patients' compliance to lifestyle changes and medical treatment.

\section{References}

1.YOUSEFZADEH, G., SHOKOOHI, M., NAJAFIPOUR, H., et al. ARYA Atheroscler, 2015, 11(3), p. 179-185.

2.SIONTIS, G.C.M., TZOULAKI, I., IOANNIDIS, J.P.A., BMJ , 2012, 3318: $1-11$.

3.DAVIES, M., KHUNTI, K., WEBB, D., et al. Updated. The handbook for vascular risk assessment, risk reduction and risk management. Leicester, 2012.

4.COLLINS, G.S., ALTMAN, D.G., BMJ , 2012, 4181: 1-12.

5.VAN STAA, T.P., GULLIFORD, M., NG, E.S., et al. PLoS One, 2014, 9(10): 106455

6.HU, S., LI, Q., GAO, P., et al. Ann Thorac Surg, 2011, 91, p. 432-438. 7.DEB, S., WIJ EYSUNDERA, H.C., KO, D.T., et al., JAMA, 2013, 310, p. 2086-2095. 
8.WINDECKER, S., KOLH, P., ALFONSO, F., et al. Eur Heart J, 2014, 35, p. 2541-2619.

9.LEVEY, A.S., STEVENS, L.A., SCHMID, C.H., ZHANG, Y.L., CASTRO, A.F., FELDMAN, H.I., KUSEK, J.W., EGGERS, P., VAN LENTE, F., GREENE, T., CORESH, J., Ann. Intern. Med., 150, no. 9, 2009, p. 604-612. 10.HIPPISLEY-COX, J., COUPLAND, C., VINOGRADOVA, Y., ROBSON, J., MAY, M., BRINDLE, P., et al., BMJ 2007; 335:136.

11.HIPPISLEY-COX, J., COUPLAND, C., VINOGRADOVA Y., et al., Heart 2008;94:34-39

12.J ENSEN, J.M., VOSS, M., HANSEN, V.B., ANDERSEN, L.K., J OHANSEN, P.B., et al., Atherosclerosis, 2012, 220: 557-562.
13.GRIMA, K.B., BEZZINA, P., RAINFORD, L. J Clin Diagn Res, 2017, 5:135. doi: 10.4172/2376-0311.1000135

14.AL NAMAT, R., AURSULESEI, V., FELEA, M.G. et al. Rev. Chim. (Bucharest), 68, no. 6, 2017, p. 1485-1489.

15.COSTACHE, I.I., AL NAMAT, R., MITU, F., CIOCOIU, M., AURSULESEI, V., MITU, O., COSTACHE, A.D., MARCU, D., BUBURUZ, A.M., Rev. Chim. (Bucharest), 68, no. 12, 2017, p. 2967.

Manuscript received: 7.10 .2018 